\title{
Electrosyntheses from Aromatic Aldehydes in a Flow Cell. Part II. The Cross-Coupling of Benzaldehydes to Unsymmetrical Diols
}

\author{
Thierry Guena and Derek Pletcher*
}

The Department of Chemistry, The University, Southampton S017 1BJ, UK

\begin{abstract}
Dedicated to Professor Lennart Eberson on the occasion of his 65th birthday

Guena, T. and Pletcher, D., 1998. Electrosyntheses from Aromatic Aldehydes in a Flow Cell. Part II. The Cross-Coupling of Benzaldehydes to Unsymmetrical Diols. - Acta Chemica Scand. 52: 32-36. (C) Acta Chemica Scandinavica 1998.

It is demonstrated that the reduction of mixtures of two benzaldehydes in acidic water-methanol in a membrane flow cell with a lead cathode can lead to a mixture of diols including the unsymmetrical diol, e.g. 4- $\mathrm{F}-\mathrm{C}_{6} \mathrm{H}_{4}-\mathrm{CH}(\mathrm{OH})$ $\mathrm{CH}(\mathrm{OH})-\mathrm{C}_{6} \mathrm{H}_{5}$. In the conditions employed, the ratio of the three diol products follows the statistical distribution expected for the coupling of two different radical intermediates produced in the same ratio as the concentrations of their precursors. The yield and current efficiency for the diols are excellent when the $\mathrm{pH}$ and potential are selected so that a $\mathrm{le}^{-}$reduction of both benzaldehydes occurs. The yield of unsymmetrical dimer based on one reactant can be increased substantially by using the other carbonyl compound as a sacrificial reagent.
\end{abstract}

It has long been recognised that the cathodic reduction of benzaldehydes leads to hydrobenzoin and/or benzyl alcohol via $1 \mathrm{e}^{-}$and $2 \mathrm{e}^{-}$reactions, respectively. ${ }^{1-3}$ In a previous paper $^{4}$ the reduction of benzaldehyde was investigated in acidic methanol-water, and it was confirmed that the mechanism of the reduction at $\mathrm{a} \mathrm{Pb}$ electrode in a flow cell was very similar to that at a dropping mercury electrode. ${ }^{5,6}$ It appears that the hydrobenzoin is formed by radical-radical coupling and it was shown that the yield of radical intermediates were highest at low negative potentials where only $1 \mathrm{e}^{-}$reduction occurs. It has also been reported that, in acidic solutions, substituted benzaldehydes also undergo reduction in two $1 \mathrm{e}^{-}$steps and that the reduction potential for the first step is insensitive to the substituent. ${ }^{1,6}$

In this paper, the parallel cathodic reduction of two benzaldehydes is investigated with a view to the synthesis of unsymmetrical diols. If the diols are, indeed, formed by the coupling of two radicals, it is to be expected that a mixture of three diols will be formed, the two symmetrical and one unsymmetrical compounds (Scheme 1). Moreover, if the radicals are generated at an equal rate, the ratio of these products will be $1: 1: 2$. In electrosynthesis, the best known example of radical-radical coupling is the Kolbe reaction. The mixed Kolbe reaction

$$
\begin{aligned}
& \mathrm{R}^{1} \mathrm{COO}^{-}+\mathrm{R}^{2} \mathrm{COO}^{-}-2 \mathrm{e}^{-} \\
& \rightarrow \mathrm{R}^{1}-\mathrm{R}^{1}+\mathrm{R}^{1-} \mathrm{R}^{2}+\mathrm{R}^{2}-\mathrm{R}^{2}
\end{aligned}
$$

\footnotetext{
* To whom correspondence should be addressed
}

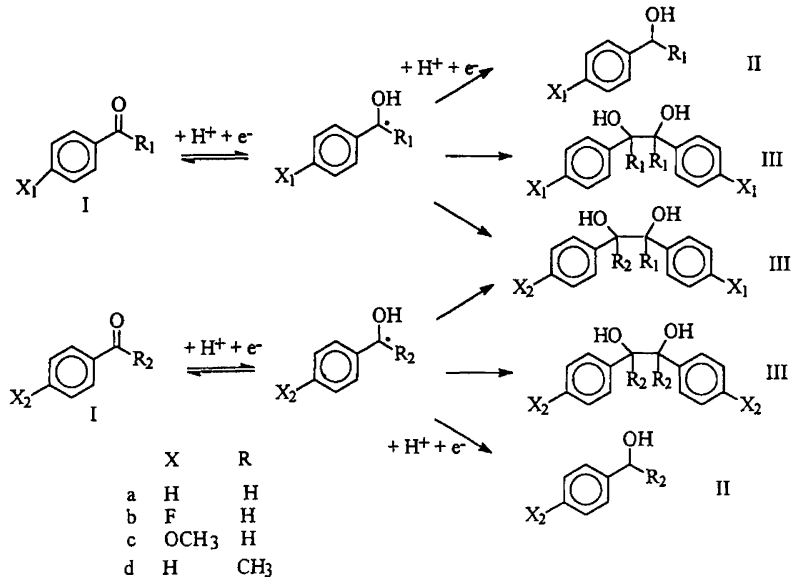

Scheme 1.

has been used to synthesise several large molecules. ${ }^{7,8}$ Moreover, it has been shown that the yield of $\mathrm{R}^{1}-\mathrm{R}^{2}$ based on $\mathrm{R}^{2} \mathrm{COO}^{-}$, can be increased beyond $50 \%$ by carrying out the electrolysis in the presence of an excess of $\mathrm{R}^{1} \mathrm{COO}^{-}$.

\section{Experimental}

The cells and the instrumentation as well as most of the experimental procedures were described in Part I of this series. ${ }^{4}$ 
Chemicals. The reactants and several products were obtained from Aldrich, Fluka or Lancaster Chemicals. They were used as received although their purity was checked by HPLC or GC.

Product identification and quantification. In general, the diols from the reduction of substituted benzaldehydes and the unsymmetrical diols were not commercially available. These products were therefore extracted and identified by proton and carbon NMR. The catholyte was neutralised with $\mathrm{Na}_{2} \mathrm{CO}_{3}$ and evaporated in vaccuum to a small volume (about $100 \mathrm{~cm}^{3}$ ) in order to eliminate any trace of methanol. Water $\left(\approx 250 \mathrm{~cm}^{3}\right)$ was then added to dissolve all the inorganic salt and the solution was extracted with ether $\left(3 \times 50 \mathrm{~cm}^{3}\right)$. The organic phase was washed with saturated solution of $\mathrm{NaCl}$, dried over $\mathrm{MgSO}_{4}$ and the ether, aldehydes and alcohols removed by evaporation in vaccuum. The diols were separated on a flash silica column (Rhone Poulenc, Sorbsil, C60/H 40-60 Mesh) with 50/50 hexane/ether.

Products from other electrolyses were identified and quantified by comparison of the HPLC retention times and peak areas with those of standard samples. The diols were always formed as a mixture of two isomers, and the pair of peaks for the threo and erythro isomers of the unsymmetrical diol always occurred between the pairs of peaks for the meso- and DL-isomers of the two symmetrical diols. For the unsymmetrical diols, their response factors were assumed to be the mean of the response factors for the two symmetrical diols.

\section{Results and discussion}

The reduction of substituted benzaldehydes and acetophenones. Figure 1 reports voltammograms for the reduction of 4-fluorobenzaldehyde $(\approx 10 \mathrm{mM})$ at a rotating lead disc electrode in methanol-water mixtures with three different $\mathrm{pH}$ values. At low $\mathrm{pH}$, two reduction waves of equal height are readily identified and the limiting currents for both waves increase with the square root of rotation rate. The reductions are therefore mass transfer controlled in the plateau regions. With increasing $\mathrm{pH}$, the first reduction wave shifts more negative by $\approx 75 \mathrm{mV}$ per $\mathrm{pH}$ unit and the two waves merge into a single reduction wave but with the same overall limiting current density. In all respects, the voltammograms are very similar to those reported at a rotating lead electrode for benzaldehyde in Part I of this series, and it is clear that reduction again occurs in two $1 \mathrm{e}^{-}$steps.

Voltammetry was carried out at the rotating lead disc for a series of benzaldehydes and two acetophenones using methanol water at $\mathrm{pH} 3$. All gave responses with two waves of equal height, and data taken from these current potential curves are reported in Table 1 . Most experiments were carried out with $20 \%$ methanol $/ 80 \%$ water, although for two aldehydes it was essential to increase the methanol content to avoid distortion of the voltammograms; this distortion was thought to arise from deposition of an insoluble product on the cathode

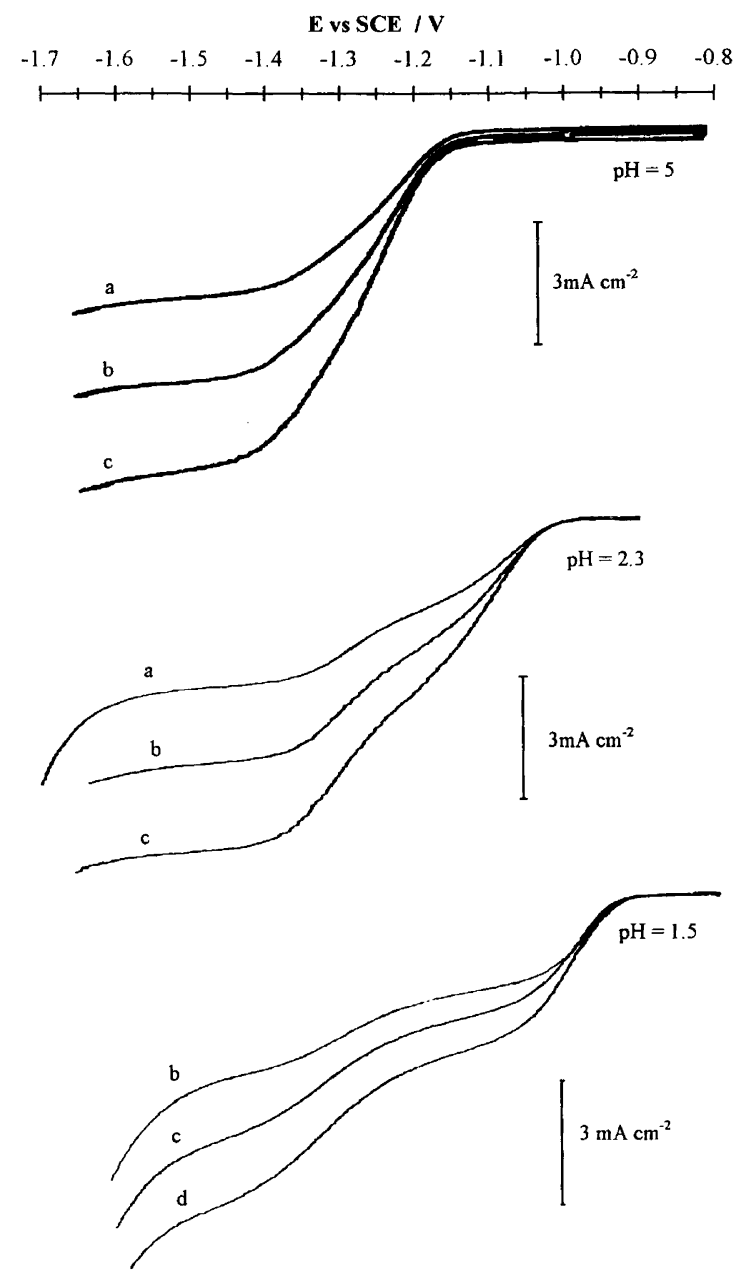

Fig. 1. Voltammograms for the reduction of 4-fluorobenzaldehyde in water-methanol media as a function of $\mathrm{pH}$ and rotation rate of the $\mathrm{Pb}$ disc electrode. Rotation rates: (a) 400 , (b) 900 , (c) 1600 and (d) 2500 r.p.m. The solutions were: $\mathrm{pH} 5.0$, 4-fluorobenzaldehyde $(10 \mathrm{mM})$ in 50/50 watermethanol containing citrate buffer $(0.2 \mathrm{M})+\mathrm{LiCl}$ $(1 \mathrm{M})+\mathrm{NaOH} . \quad \mathrm{pH} 2.3$, 4-fluorobenzaldehyde $(10 \mathrm{mM})$ in $80 / 20$ water-methanol containing citrate buffer $(0.2 \mathrm{M})+\mathrm{LiCl}$ $(1 \mathrm{M})+\mathrm{HCl}$. pH 1.5, 4-fluorobenzaldehyde $(8.6 \mathrm{mM})$ in 50/50 water-methanol containing $\mathrm{Li}_{2} \mathrm{SO}_{4}(0.5 \mathrm{M})+\mathrm{H}_{2} \mathrm{SO}_{4}$.

surface. It can be seen from the table that the acetophenones are slightly more difficult to reduce than the benzaldehydes, but the half-wave potentials for both the benzaldehydes and acetophenones are only slightly sensitive to the nature of the substituent. For example, for all the benzaldehydes studied, $E_{1 / 2}$ varies by $<100 \mathrm{mV}$. It can be seen that the first reduction wave is steep, and $E_{1 / 4}-E_{3 / 4}$ is close to the value for a reversible electrontransfer process and hence, for all compounds studied, eqns. (1)-(5) in Part I appear to describe the reduction mechanism satisfactorily.

Voltammograms were also recorded for 4-fluorobenzaldehyde and 4-methoxybenzaldehyde in the FM01 cell with $10 \mathrm{~cm}^{2}$ lead cathode using a catholyte with $\mathrm{pH} 3$. For both aldehydes the voltammograms are very similar to those at the rotating disc electrode; two waves 
Table 1. Data from the voltammograms for the reduction of benzaldehydes and acetophenones $(\approx 10 \mathrm{mM})$ at a rotating $\mathrm{Pb}$ disc electrode in $20 \%$ methanol $/ 80 \%$ water containing $\mathrm{LiCl}(1 \mathrm{M})$ and citrate buffer $(0.2 \mathrm{M})$ at $\mathrm{pH} 3$. Rotation rate $900 \mathrm{r}$.p.m.

\begin{tabular}{|c|c|c|c|c|c|}
\hline & \multicolumn{2}{|c|}{ First reduction wave } & \multicolumn{2}{|c|}{ Second reduction wave } & \multirow[b]{2}{*}{$j_{\mathrm{L}}^{a} / \mathrm{mA} \mathrm{cm}{ }^{-2}$} \\
\hline & $-E_{1 / 2}$ vs. SCE $/ \mathrm{V}$ & $E_{1 / 4}-E_{3 / 4} / \mathrm{mV}$ & $-E_{1 / 2}$ vs. SCE $/ \mathrm{V}$ & $E_{1 / 4}-E_{3 / 4} / \mathrm{mV}$ & \\
\hline Benzaldehyde & 1.08 & 70 & 1.26 & 90 & 6.0 \\
\hline 4-Fluorobenzaldehyde & 1.09 & 70 & 1.30 & 90 & 5.5 \\
\hline 4-Methylbenzaldehyde $e^{b}$ & 1.10 & 70 & 1.30 & 90 & 5.9 \\
\hline 4-tert-Butylbenzaldehyde ${ }^{c}$ & 1.11 & 80 & 1.41 & 90 & 6.3 \\
\hline 4-Methoxybenzaldehyde & 1.15 & 60 & 1.40 & 80 & 5.2 \\
\hline Acetophenone & 1.18 & 50 & 1.42 & 80 & 4.7 \\
\hline 4-Methylacephenone & 1.21 & 50 & 1.55 & 80 & 4.5 \\
\hline
\end{tabular}

${ }^{a} j_{L}$ is the limiting current density for the sum of the two reduction waves. ${ }^{b} 50 / 50 \mathrm{MeOH} / \mathrm{H}_{2} \mathrm{O}$. ${ }^{c} 80 / 20 \mathrm{MeOH} / \mathrm{H}_{2} \mathrm{O}$ with decreased salt concentration.

of equal height are observed with, for example, $E_{1 / 2}=$ $-1.08 \mathrm{~V}$ and $-1.30 \mathrm{~V}$ for 4 -fluorobenzaldehyde. The limiting currents show a strong catholyte flow rate dependence confirming that the reductions are mass transport controlled.

Controlled potential reduction of the substituted benzaldehydes and acetophenones in the FMOl flow cell. A series of electrolyses were carried out in the FM01 flow cell with the objective of confirming that the diol could be formed in good yield. Hence, electrolyses employed a potential in the first wave of the voltammograms reported above and, in general, a low $\mathrm{pH}$ was preferred. ${ }^{4}$ The results are reported in Table 2 , where it can be seen that, for all four carbonyl compounds studied, the yield and current efficiency for the product diol exceeded $70 \%$. Some alcohol is, however, almost always also isolated, and if the electrolyses are carried out at a potential in the plateau of the second wave, the alcohol can be isolated with yields and current efficiencies $>80 \%$. For the 4-fluorobenzaldehyde, it was further confirmed that the coupling shows no stereoselectivity: the DL/meso ratio estimated by NMR was $48 / 52$.
The cross-coupling of two carbonyl compounds to unsymmetrical diols. The voltammograms for benzaldehyde and 4-fluorobenzaldehyde are very similar, see Table 1, and hence these aldehydes were selected for the preliminary experiments. Moreover, voltammograms for a solutions containing both benzaldehyde ( $5 \mathrm{mM}$ ) and 4-fluorobenzaldehyde $(5 \mathrm{mM})$ at both the rotating $\mathrm{Pb}$ disc electrode and in the flow cell were effectively identical to the responses for either aldehyde alone $(10 \mathrm{mM})$.

A series of preparative scale electrolyses were carried out in the flow cell for solutions where the total aldehyde concentration was $10 \mathrm{mM}$, but the ratio benzaldehyde/ 4-fluorobenzaldehyde was varied. At potentials in the plateau of the second wave, the only products were the two benzyl alcohols, and ratio of benzyl alcohol/ 4-fluorobenzyl alcohol only reflects the ratio of aldehydes in the initial solution. The results from electrolyses at a potential close to the plateaux of the first waves are reported in Table 3. It is clear that, for all ratios of benzaldehyde/4-fluorobenzaldehyde, the diols are the major products and the ratio of total diols to total alcohols is almost constant. Both threo and erythro isomers of the unsymmetrical diol are always observed

Table 2. The influence of $\mathrm{pH}$ and cathode potential on the products from the reduction of benzaldehyde at several $\mathrm{pH}$. $\mathrm{FM} 01$ cell with $10 \mathrm{~cm}^{2} \mathrm{~Pb}$ cathode and turbulence promoter. Initial benzaldehyde concentration $\approx 7-10 \mathrm{mM}$. Room temperature. Mean linear electrolyte flow rate $9.9 \mathrm{~cm} \mathrm{~s}^{-1}$. Electrolyte compositions: $\mathrm{pH} 1.5, \mathrm{Li}_{2} \mathrm{SO}_{4}(0.5 \mathrm{M})+\mathrm{H}_{2} \mathrm{SO}_{4}$ in $20 / 80 \mathrm{MeOH}-\mathrm{H}_{2} \mathrm{O}$ and $\mathrm{pH} 3.0$, Li citrate $(0.2 \mathrm{M})+\mathrm{LiCl}(1 \mathrm{M})$ in $10 / 90 \mathrm{MeOH}-\mathrm{H}_{2} \mathrm{O}$.

\begin{tabular}{|c|c|c|c|c|c|c|c|c|}
\hline \multirow[b]{2}{*}{ III } & \multirow[b]{2}{*}{$\mathrm{pH}$} & \multirow[b]{2}{*}{$E / V$ vs. SCE } & \multirow[b]{2}{*}{$j_{t=0} / \mathrm{mA} \mathrm{cm}^{-2}$} & \multicolumn{3}{|c|}{ Product distribution ${ }^{a}$ after $0.6 \mathrm{~F}(\%)$} & \multicolumn{2}{|c|}{ Current efficiency $(\%)$} \\
\hline & & & & $\mathbf{I}$ & II & III & II & III \\
\hline Benzaldehyde & $\begin{array}{l}1.5 \\
3\end{array}$ & $\begin{array}{r}-1.00 \\
-1.05 \\
-1.15\end{array}$ & $\begin{array}{l}2.0 \\
2.4 \\
3.0\end{array}$ & $\begin{array}{l}49 \\
45 \\
60\end{array}$ & $\begin{array}{l}3 \\
8 \\
8\end{array}$ & $\begin{array}{l}39 \\
31 \\
15\end{array}$ & $\begin{array}{r}9 \\
28 \\
28\end{array}$ & $\begin{array}{l}64 \\
56 \\
27\end{array}$ \\
\hline 4-Fluorobenzaldehyde & $\begin{array}{l}1.5 \\
3\end{array}$ & $\begin{array}{l}-1.10 \\
-1.15\end{array}$ & $\begin{array}{l}2.1 \\
3.5\end{array}$ & $\begin{array}{l}47 \\
45\end{array}$ & $\begin{array}{l}7 \\
8\end{array}$ & $\begin{array}{l}44 \\
38\end{array}$ & $\begin{array}{l}23 \\
26\end{array}$ & $\begin{array}{l}74 \\
63\end{array}$ \\
\hline 4-Methoxybenzaldehyde & 1.5 & -1.15 & 2.5 & 49 & 1 & 42 & 5 & 70 \\
\hline Acetophenone & 1.5 & -1.10 & 1.4 & 41 & 0 & 36 & 0 & 72 \\
\hline
\end{tabular}

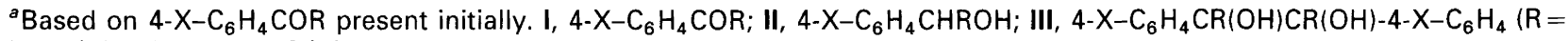
$\mathrm{H}$ or $\mathrm{CH}_{3}, \mathrm{X}=\mathrm{H}, \mathrm{F}$ or $\mathrm{OCH}_{3}$ ). 
Table 3. Reduction of mixtures of benzaldehyde and 4-fluorobenzaldehyde in $50 \%$ methanol $/ 50 \%$ water containing $\mathrm{Li}_{2} \mathrm{SO}_{4}$ $(0.5 \mathrm{M})$ and adjusted to $\mathrm{pH} 1.5$ with $\mathrm{H}_{2} \mathrm{SO}_{4}$ in the FM01 flow cell with $10 \mathrm{~cm}^{2} \mathrm{~Pb}$ cathode. ${ }^{a}$

\begin{tabular}{|c|c|c|c|c|c|c|c|c|c|c|c|c|}
\hline \multirow{2}{*}{$\begin{array}{l}\text { Ratio } \\
\text { la/lb }\end{array}$} & \multicolumn{2}{|c|}{ Current efficiency $(\%)$} & \multicolumn{7}{|c|}{ Product distribution ${ }^{b}$ after $0.6 \mathrm{~F}(\%)$} & \multicolumn{3}{|c|}{$\begin{array}{l}\text { Yields of fluorinated } \\
\text { products }^{b}(\%)\end{array}$} \\
\hline & $\Sigma I I$ & $\Sigma I I I$ & la & lb & Ila & Illb & IIla & $\mathrm{III}_{\mathrm{a}}^{\mathrm{b}}$ & Illlb & Illb & IIIb & $\mathrm{III}_{\mathrm{a}}^{\mathrm{b}}$ \\
\hline $85 / 15$ & 10 & 64 & 37 & 7 & 3 & 0 & 26 & 9 & 4 & 0 & 45 & 55 \\
\hline $52 / 48$ & 10 & 67 & 26 & 24 & 2 & 2 & 13 & 18 & 9 & 6 & 39 & 38 \\
\hline $11 / 89$ & 18 & 67 & 6 & 43 & 0 & 5 & 2 & 6 & 33 & 12 & 73 & 6 \\
\hline
\end{tabular}

${ }^{a}$ Cathode potential $-1.10 \mathrm{~V}$ vs. SCE. Total initial aldehyde concentration $\approx 10 \mathrm{mM}$. Room temperature. Mean linear electrolyte

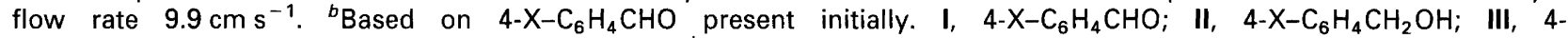
$X-\mathrm{C}_{6} \mathrm{H}_{4} \mathrm{CH}(\mathrm{OH}) \mathrm{CH}(\mathrm{OH})-4-\mathrm{X}-\mathrm{C}_{6} \mathrm{H}_{4}$, a: $\mathrm{X}=\mathrm{H}, \mathrm{b}: \mathrm{X}=\mathrm{F}$. III $\mathrm{a}, 4-\mathrm{F}-\mathrm{C}_{6} \mathrm{H}_{4} \mathrm{CH}(\mathrm{OH}) \mathrm{CH}(\mathrm{OH}) \mathrm{C}_{6} \mathrm{H}_{5}$.

in equal amounts, but their maximum total concentration is obtained when the initial concentration of the two reactants are equal.

If the $1 \mathrm{e}^{-}$reduction of benzaldehydes leads to free radical intermediates, the relative concentrations of the radicals are the same as their precursors and the radicalradical coupling reactions are diffusion controlled, it is possible to calculate the ratio of the three diols formed in the electrolyses using an equation based on a standard statistical argument. ${ }^{9}$ Table 4 compares the calculated and experimental ratios, and it can be seen that the agreement is compelling. In view of the similarity of the current-potential curves for benzaldehyde and 4-fluorobenzaldehyde, it is reasonable to postulate that the rate of conversion of reactant to intermediate will be very similar for the two compounds. Hence, this comparison provides good evidence that the diols are formed by the coupling of free radical intermediates. Indeed, it is perhaps the clearest evidence yet for free radical intermediates in the reduction of benzaldehydes in acidic solvent-water mixtures.

When the synthesis of a large organic molecule involves coupling of one 'expensive' and one 'cheap' substrate, it is common to quote yields based on the more expensive reagent and even to treat the cheaper substrate as a sacrificial reagent, i.e. consume an excess of the cheaper substrate in order to maximise the yield of the desired product based on the more expensive substrate. The yields of fluorinated products from the electrolyses of mixtures of benzaldehyde and 4-fluorobenzaldehyde were therefore recast into yields based on the consumption of 4-fluorobenzaldehyde (considered to be the more expensive substrate), and these data are also reported in Table 3.
It evident that the yield of the desired unsymmetrical dimer, based on the consumption of 4-fluorobenzaldehyde, can be enhanced by the presence of a large excess of benzaldehyde, although this is wasteful of both benzaldehyde and electrical energy because the current efficiency becomes lower.

A further series of electrolyses at $-1.10 \mathrm{~V}$ vs. SCE and a $\mathrm{pH}$ of 1.5 used a constant concentration of 4fluorobenzaldehyde ( $5 \mathrm{mM})$ and a variable concentration of benzaldehyde (1-20 mM). All the above conclusions were confirmed. The total yield of diols was always high while the ratio of three diols, IIIa, III $_{\mathbf{a}}^{\mathrm{b}}$ and $\mathbf{I I I b}$, agreed well with those calculated statistically making the same assumptions as above. In the electrolysis with $20 \mathrm{mM}$ benzaldehyde, the yield of the unsymmetrical diol, 4fluorohydrobenzoin was $57 \%$ based on the consumption of 4-fluorobenzaldehyde.

The mixed coupling of (a) 4-fluorobenzaldehyde and 4-methoxybenzaldehyde and (b) benzaldehyde and acetophenone were also investigated and the results are reported in Tables 5 and 6 . In the conditions selected, the total current efficiencies as well as the overall yield of diols from both reactions are good. Moreover, for all electrolyses, the ratio of the three diols can be calculated assuming that the relative concentrations of the radicals are the same as their precursors, and the radical-radical coupling reactions are controlled only by statistics. With equal concentrations of the two reactants, the yield of the unsymmetrical dimer is ca. $20 \%$. The yield based on one carbonyl can be increased at the cost of inefficient use of the other carbonyl compound as well as electrical energy.

Table 4. Comparison of the experimental ratio of diols to the ratios calculated assuming that the $1 \mathrm{e}^{-}$reduction of benzaldehydes leads to free radical intermediates, the relative concentrations of the radicals is the same as their precursors and the radical-radical coupling reactions are controlled only by statistics. For electrolysis conditions and definition of symbols, see Table 3.

\begin{tabular}{|c|c|c|c|c|c|c|}
\hline \multirow{2}{*}{$\begin{array}{l}\text { Ratio } \\
\text { la/lb }\end{array}$} & \multicolumn{3}{|c|}{ Experimental ratio of diols } & \multicolumn{3}{|c|}{ Calculated ratio of diols } \\
\hline & IIla & $\mathrm{III}_{\mathrm{a}}^{\mathrm{b}}$ & IIIlb & IIla & $\mathrm{III}_{\mathrm{a}}^{\mathrm{b}}$ & IIllb \\
\hline $85 / 15$ & 0.67 & 0.23 & 0.09 & 0.73 & 0.25 & 0.02 \\
\hline $52 / 48$ & 0.32 & 0.45 & 0.23 & 0.27 & 0.50 & 0.23 \\
\hline $11 / 89$ & 0.04 & 0.13 & 0.83 & 0.01 & 0.20 & 0.79 \\
\hline
\end{tabular}


Table 5. Reduction of mixtures of 4-methoxybenzaldehyde and 4-fluorobenzaldehyde in $50 \%$ methanol/50\% water containing $\mathrm{Li}_{2} \mathrm{SO}_{4}(0.5 \mathrm{M})$ and adjusted to $\mathrm{pH} 1.5$ with $\mathrm{H}_{2} \mathrm{SO}_{4}$ in the FM01 flow cell with $10 \mathrm{~cm}^{2} \mathrm{~Pb}$ cathode. ${ }^{2}$

\begin{tabular}{|c|c|c|c|c|c|c|c|c|c|}
\hline \multirow{2}{*}{$\begin{array}{l}\text { Ratio } \\
\text { lb//c }\end{array}$} & \multicolumn{2}{|c|}{ Current efficiency $(\%)$} & \multicolumn{7}{|c|}{ Product distribution $^{b}$ after $0.6 \mathrm{~F}(\%)$} \\
\hline & $\Sigma I I$ & $\Sigma$ III & lb & Ic & IIb & IIc & IIIb & $\mathrm{III}_{\mathrm{b}}^{\mathrm{c}}$ & IIIc \\
\hline $18 / 82$ & 3 & 69 & 12 & 37 & $<1$ & $<1$ & 0 & 8 & 34 \\
\hline $50 / 50$ & 2 & 65 & 20 & 24 & 1 & 0 & 7 & 21 & 11 \\
\hline $89 / 11$ & 0 & 84 & 28 & 6 & 0 & 0 & 40 & 10 & 1 \\
\hline
\end{tabular}

${ }^{a}$ Cathode potential $-1.15 \mathrm{~V}$ vs. SCE. Total initial aldehyde concentration $\approx 10 \mathrm{mM}$. Room temperature. Mean linear electrolyte flow rate $9.9 \mathrm{~cm} \mathrm{~s}^{-1}$. ${ }^{b}$ Based on $4-\mathrm{X}-\mathrm{C}_{6} \mathrm{H}_{4} \mathrm{CHO}$ present initially. I, 4- $\mathrm{X}-\mathrm{C}_{6} \mathrm{H}_{4} \mathrm{CHO} \mathrm{II}, 4-\mathrm{X}_{-} \mathrm{C}_{6} \mathrm{H}_{4} \mathrm{CH}_{2} \mathrm{OH}$; III, 4$X-\mathrm{C}_{6} \mathrm{H}_{4} \mathrm{CH}(\mathrm{OH}) \mathrm{CH}(\mathrm{OH})-4-\mathrm{X}-\mathrm{C}_{6} \mathrm{H}_{4}$. b: $X=\mathrm{F}, \mathrm{c}: \mathrm{X}=\mathrm{OCH}_{3}$. III c , 4-F- $\mathrm{C}_{6} \mathrm{H}_{4} \mathrm{CH}(\mathrm{OH}) \mathrm{CH}(\mathrm{OH})-4-\mathrm{CH}_{3} \mathrm{OC}_{6} \mathrm{H}_{4}$.

Table 6. Reduction of mixtures of benzaldehyde and acetophenone in $50 \%$ methanol/50\% water containing $\mathrm{Li}_{2} \mathrm{SO}_{4}(0.5 \mathrm{M})$ and adjusted to $\mathrm{pH} 1.5$ with $\mathrm{H}_{2} \mathrm{SO}_{4}$ in the $\mathrm{FM01}$ flow cell with $10 \mathrm{~cm}^{2} \mathrm{~Pb}$ cathode. ${ }^{a}$

\begin{tabular}{|c|c|c|c|c|c|c|c|c|c|c|}
\hline \multicolumn{2}{|c|}{ Initial concentrations } & \multicolumn{2}{|c|}{ Current efficiency (\%) } & \multicolumn{7}{|c|}{ Product distribution ${ }^{b}$ after $0.6 \mathrm{~F}(\%)$} \\
\hline$[\mathbf{l a}] / \mathrm{mM}$ & {$[\mathbf{I d}] / \mathrm{mM}$} & $\Sigma I I$ & $\Sigma$ III & la & lb & Ila & IId & IIIa & $\mathbf{I I I}_{\mathrm{a}}^{\mathrm{d}}$ & IIId \\
\hline 3 & 9.5 & $<1$ & 80 & 11 & 32 & 0 & 0 & 2 & 19 & 27 \\
\hline 11 & 9.5 & 2 & 72 & 26 & 17 & 0 & $<1$ & 12 & 22 & 10 \\
\hline 35 & 9.5 & 2 & 99 & 15 & 7 & 0 & $<1$ & 39 & 18 & 3 \\
\hline
\end{tabular}

${ }^{a}$ Cathode potential $-1.10 \mathrm{~V}$ vs. SCE. Total initial aldehyde concentration $\approx 10 \mathrm{mM}$. Room temperature. Mean linear electrolyte flow rate $9.9 \mathrm{~cm} \mathrm{~s}^{-1}$. ${ }^{b}$ Based on $\mathrm{C}_{6} \mathrm{H}_{5} \mathrm{COR}$ present initially. I, $\mathrm{C}_{6} \mathrm{H}_{5} \mathrm{COR} ; \mathrm{II}, \mathrm{C}_{6} \mathrm{H}_{5} \mathrm{CH}(\mathrm{OH}) \mathrm{R} ; \mathrm{III}, \mathrm{C}_{6} \mathrm{H}_{5} \mathrm{CR}(\mathrm{OH}) \mathrm{CR}(\mathrm{OH})-\mathrm{C}_{6} \mathrm{H}_{5}$. a: $\mathrm{R}=\mathrm{H}, \mathrm{b}: \mathrm{R}=\mathrm{CH}_{3}$. III $\mathrm{a}_{6} \mathrm{C}_{5} \mathrm{CH}(\mathrm{OH}) \mathrm{C}\left(\mathrm{CH}_{3}\right)(\mathrm{OH}) \mathrm{C}_{6} \mathrm{H}_{5}$.

\section{Conclusions}

The data from the electrolysis of mixtures of two carbonyl compounds provide compelling evidence that the reduction of such molecules in aqueous acidic media occurs via free radical intermediates. With appropriate selection of the cathode potential (and also $\mathrm{pH}$ ), it is possible to obtain good current efficiencies for the formation of the $1 \mathrm{e}^{-}$products, the diols. With a mixtures of two carbonyl compounds, three diols are always observed, and in all experiments reported here their ratio can be calculated by simple statistics from the relative concentrations of the two reactants. Hence, the yield of unsymmetrical diol, of potential interest in synthesis, is only ca. $20 \%$ when the two carbonyl compounds are present in equal concentration. The yield based on one carbonyl compound can be increased by using the other as a sacrificial reagent. The statistical calculations assume that the relative concentration of radicals is the same as the carbonyl compounds in the catholyte. This will be the case if the voltammograms for the two carbonyl compounds are similar or the potential is selected so that the reduction of both carbonyl compounds are mass transport controlled. If, however, the two carbonyl compounds have significantly different current/potential responses, it should be possible to vary the ratio of diols by selecting a potential where the two radicals are produced at significantly different rates. For example, if the potential is chosen in the foot of the reduction wave for the more difficult to reduce carbonyl compound, then the selectivity will be different from that described here. Again, this should allow a significant increase in the yield of mixed diol based on the more difficult to reduce aldehyde. The other aldehyde would, however, still be a sacrificial reagent.

Acknowledgements. This work was supported by the European Commission through the Human Capital \& Mobility Scheme, contract no. ERBCHRXCT920073. We also gratefully acknowledge the interest and advice of other members of the Network 'Activation of Organic Molecules by Electron Transfer'. Finally, we thank ICI Chemicals \& Polymers Ltd. for the loan of the FM01 LC Electrolyser.

\section{References}

1. Evans, D. H. In: Bard, A. J. and Lund H., Eds., Encyclopedia of Electrochemistry of the Elements - Organic Section, Part XII, Marcel Dekker, New York 1978.

2. Fry, A. J. Synthetic Organic Electrochemistry, 2nd Edn., Wiley Interscience, New York 1989, p. 174.

3. Baizer, M. M. In: Lund, H. and Baizer, M. M., Eds., Organic Electrochemistry - An Introduction and a Guide, 3rd Edn., Marcel Dekker, New York 1991, Chaps. 10 and 22.

4. Guena, T. and Pletcher, D. Acta Chem. Scand. 52 (1998) 23.

5. Zuman, P., Barnes, D. and Ryvolová-Kejharovå, A., Discuss. Faraday Soc. 45 (1968) 202.

6. Zuman, P. Substituent Effects in Organic Polarography, Plenum, New York, 1967.

7. Schäfer, H. J. Top. Curr. Chem. 152 (1990) 91.

8. Genders, J. D. and Pletcher, D. Chem. Ind. (1996) 682.

9. Pryor, W. A. Free Radicals, McGraw Hill, New York 1966, p 14-15.

Received January 8, 1997. 